\title{
QUANTITATIVE ASSESSMENT OF THE DYNAMIGS OF SOCIOECONOMIC PROCESSES
}

\author{
Romualdas Ginevičius $^{1 *}$, Martin Schieg ${ }^{2}$, Magdalena Kot-Radojewska ${ }^{3}$ \\ and Marta Jarocka ${ }^{4}$ \\ ${ }^{1), 4)}$ Bialystok University of Technology, Biatystok, Poland \\ ${ }^{2)}$ Technical University of Munich, Munich, Germany \\ 3) WSB University, Dabrowa, Poland
}

Please cite this article as:

Ginevičius, R., Schieg, M., Kot-Radojewska, M. and Jarocka, M., 2021. Quantitative Assessment of the Dynamics of Socioeconomic Processes. Amfiteatru Economic, 23(57), pp.504-516.

DOI: $10.24818 / \mathrm{EA} / 2021 / 57 / 504$

\section{Article History}

Received: 27 December 2020

Revised: 10 January 2021

Accepted: 12 March 2021

\begin{abstract}
The efficiency of correlation-regression analysis would significantly expand if both of its essential variables - a dependent and an independent - conveyed the information on the dynamic rather than static state of a phenomenon under consideration. For this objective, the dynamic development of the socioeconomic processes should be based on the quantitative assessment. Existing methodologies call for improvement as they do not fully reflect the state of particular phenomena. In this article, authors provide the quantitative assessment methodology to analyse the dynamics of socioeconomic processes. It was applied for assessing real situations, which confirmed adequacy and applicability of this methodology.
\end{abstract}

Keywords: socioeconomic processes, their fluctuations, quantitative assessment of the fluctuation dynamics.

JEL Classification: C13, C61, B16

\footnotetext{
* Corresponding author, Romualdas Ginevičius - e-mail: romualdas.ginevicius@vgtu.lt

\section{Authors' ORCID:}

Romualdas Ginevičius: orcid.org/0000-0003-2067-4398

Martin Schieg: orcid.org/0000-0003-0843-7605

Magdalena Kot-Radojewska: orcid.org/0000-0002-7323-1913

Marta Jarocka: orcid.org/0000-0002-2610-8007
} 


\section{Introduction}

All economic agents that conduct production, service provision, maintenance, consumption and similar processes belong to particular socioeconomic systems, i.e. the social systems incorporating material, technical, informational and other resources. In order to survive, they need to be in constant evolvement process. It is a condition of their existence. Development refers to the changes in system parameters. Evolution of these changes, ongoing consistently in the course of time, forms the development process. Thus, development is a process. Because it is a process of a socioeconomic system development, it can be understood as a socioeconomic process (SEP) (Ginevicius, et al., 2018). It defines the situation in a socioeconomic system.

Correlation-regression is the most universal and most common method of the SEP analysis and fluctuation forecast. It is based on determination of the strength and nature of the effects that independent variables, or determinants, have on the phenomenon under consideration. The core of regression analysis is the correlation field which helps to determine the nature of the effect. A point in this field represents the intersection between a dependent and an independent variable. If an independent variable, for instance, represents the condition of the SEP development over particular time period, and a dependent variable represents the value of a particular determinant affecting the condition of the phenomenon researched, the question arises as to how informative the abovementioned point is, i.e. how much and what sort of information the point has accumulated. From what the point reflects, it becomes clear that it represents the information about the statistical condition of the SEP, but it does not provide the information on the nature of the development of either a dependent or an independent variable. On the other hand, if a point in the correlation field represents the intersection between the development of an independent variable over particular period and the development of a dependent variable over the same period, it will contain an incomparably larger amount of information as it will reflect a dynamic rather than a static condition of the variables, i.e. it will indicate long-term fluctuations and tendencies. Hence, if a correlation-regression analysis incorporates the variables that reflect a dynamic rather than a static condition, it provides more opportunities to raise research efficiency and expand applicability and adequacy of the results because it indicates how long-term fluctuations and trends affect the long-term changes in the phenomena under research.

\section{The potential of quantitative assessment of the dynamics for the SEP development}

Being multiple and complex by their nature, socioeconomic processes are affected by a number of destabilising factors. Together, they form the environment that requires a constant adaptation. The result of such situation is that the development of the socioeconomic processes is not ideal, i.e. it is not smooth, and its intensity may vary in different time slots. The development is considered to be ideally smooth, if an increase in the SEP development is equal over all time slots during the entire period under consideration, i.e. if $\Delta q_{i}=\Delta q_{i+1}$; here $\Delta q_{i}$ represents an increase in the SEP development over the $i^{\text {th }}$ time slot of the entire period $T$, e.g. a year $(i=\overline{1, n})$. In this case, an ideal trajectory of the SEP development would look as depicted in Figure no. 1: 


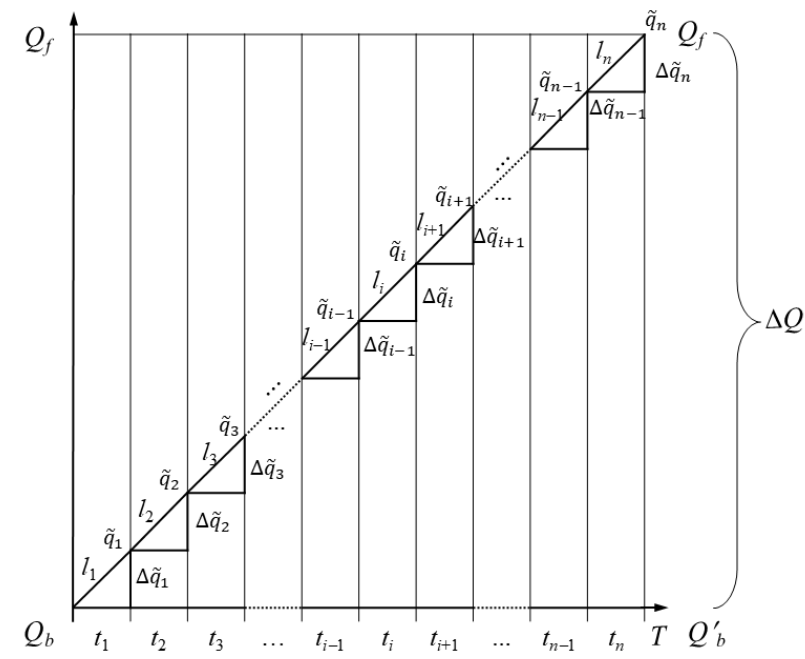

Figure no. 1. An ideal trajectory of the SEP development over period T

The efforts of a socioeconomic system to adapt to its environment distort the ideal trajectory of the SEP development depicted in Figure 1, i.e. an increase in the SEP development over time slot $t_{i+1}$ is not equal to an increase over time $t_{i}$. The factual trajectory (see Figure no. 2) of the SEP development represents real situation.

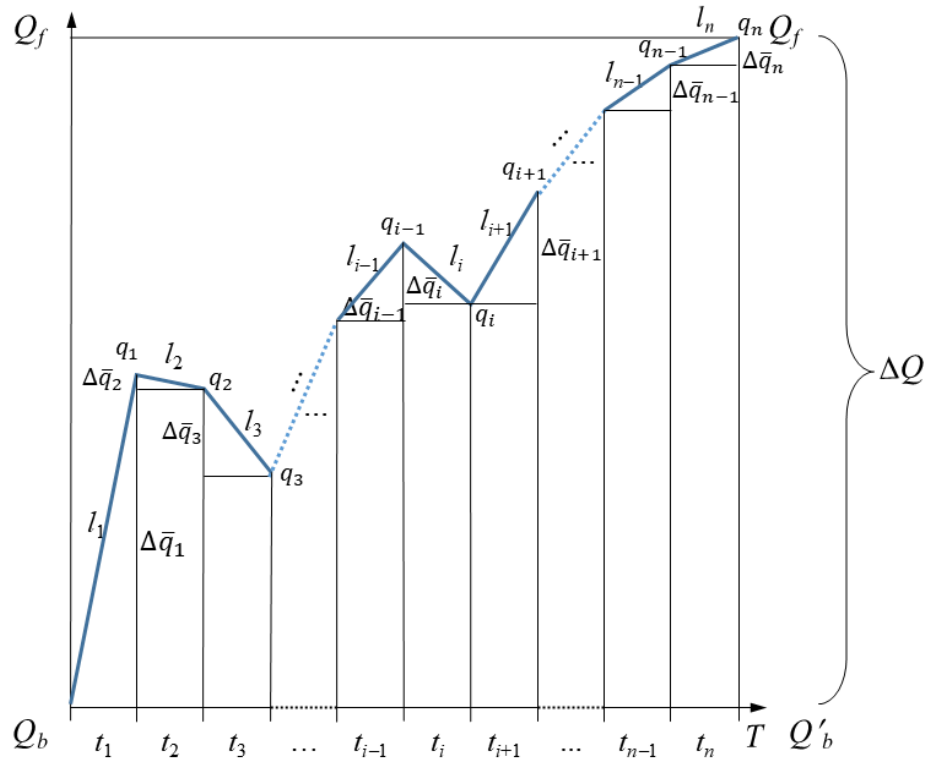

Figure no. 2. The factual SEP development during the analysed time period

The method of Measuring of Dynamics of Development (MDD) is proposed as the one that allows to quantitatively assess the factual trajectory of the SEP development depicted in Figure no. 2. Based on this method, the dynamics of economic development was estimated for a group of the EU member states (Ginevičius, et al., 2018). The SEP development itself 
compromises two sides - qualitative and quantitative, which represents the intensity of the development and also the smoothness of the process. The combination of both indicators produces and integrated indicator, which could be applied for the analysis of the dynamics of SEP development.

The smoothness indicator calculated as the ratio of the length of the analysed time period and the length of the SEP development factual trajectory over this time period. The length of the factual trajectory is based on the development fluctuations over the particular time slots of the entire period researched (a year). The fluctuations are expressed as the difference between the development values based on two adjacent time slots. The length of the SEP development factual trajectory over the entire period under consideration is a diagonal of a right triangle. One perpendicular of this triangle is the difference between the development values estimated for nearby time slots, while the other perpendicular is the length of the entire analysed period. For this situation, the length $l_{i}$ of the diagonal line of the right triangle $i$ is estimated as follows (Ginevičius et al.,2018):

$l_{i}=\sqrt{1+\Delta q_{i}^{2}}$.

The length $L_{i}$ of the SEP development factual trajectory over the entire analysed time period $T$ is equal to the sum of the values $l_{i}$ :

$L_{T}=\sum_{i=1}^{N} l_{i}$.

The indicator $D_{T}$ represents the SEP development smoothness over the analysed period $T$ is estimated by formula:

$D_{T}=\frac{T}{L_{i}}$

Intensity, another partial indicator of the SEP development dynamics, is evaluated as the ratio of of the SEP development the value at the start of period $T$ and the SEP development value at the end of this period:

$D_{I}=\frac{Q_{f}}{Q_{b}}$,

here $D_{I}$ represents intensity of the SEP development over the entire period $T ; Q_{f}$ marks the value the SEP development at the beginning of period $T ; Q_{b}$ stands for the value of the SEP development at the end of period $T$.

The main SEP development dynamics indicator is described as the result of the development smoothness and intensity factors:

$D=D_{T} \cdot D_{I}$

\section{SEP development dynamics quantitative assessment methodology}

Practical application of the MDD methodology for quantitative assessment of the SEP development dynamics revealed that this methodology calls for improvement. As it can be 
seen in Figure no. 2, the length of one perpendicular in the right triangle in time slot $i$ over the period $T$ is equal to the difference in the values at the beginning and the end of this time slot. The length of the other perpendicular is evaluated based on the duration of period $T$ (in years), is divided by the number years. For example, if $T=10$ years, it covers 10 time slots. In this case, length $l_{i}$ of the perpendicular is equal to $l_{i}=10: 10=1$.

In order to improve the existing methodology and not to abandon its principles, it is necessary to clarify the estimation of both the ideal and factual trajectories of the SEP development and calculate the development intensity indicator.

Evaluation of the SEP development ideal trajectory length. Based on MDD methodology, this length is equal to the duration of period $T$. In essence, a separate case of the SEP development is faced when no increase in the development is recorded during all time slots of period $T$, i.e. $\Delta q=\Delta q_{i+1}$. The indicators of the SEP development show that such cases are practically non-existent because any process functions only when it evolves. Thus, real processes develop with varying intensity.

The structure of the ideal trajectory length estimation for the SEP development over time period $T$ is represented in Figure no. 1 which shows that the length of this trajectory is equal to the length of the diagonal line $Q_{b} Q_{f}$ in the triangle $Q_{b} Q_{f} Q^{\prime}{ }_{b}$. It is represented in following formula (Ginevičius, et al., 2018):

$L_{T}=\sqrt{T^{2}+\Delta Q^{2}}$,

$L_{T}-$ the length of SEP development ideal trajectory.

$L_{T}$ is equal to the sum of the SEP development ideal trajectories lengths in different time slots over period $T$ (Figure no. 1):

$L_{T}=\sum_{i=1}^{n} l_{i}$

$l_{i}$ is the SEP development ideal trajectory length in $i^{\text {th }}$ time slot over period $T$.

The SEP development value for $i^{\text {th }}$ time slot corresponding to the ideal trajectory of the SEP development over the period under consideration is estimated as follows:

$\Delta \tilde{q}_{i}=Q_{b}+i \frac{\Delta Q}{n}$,

$\Delta \tilde{q}_{i}$ is the value of the SEP development for $i^{\text {th }}$ time slot represented by the ideal trajectory of the SEP development.

Evaluation of the SEP development factual trajectory length. Accordingly, in previously described method for the SEP development ideal trajectory length, the factual trajectory length of the of the SEP development in $i^{\text {th }}$ time slot over period $T$ is evaluated based on the triangle $\Delta q_{i} \Delta q_{i+1} \Delta q_{i}^{\prime}$ (Figure no. 3). 


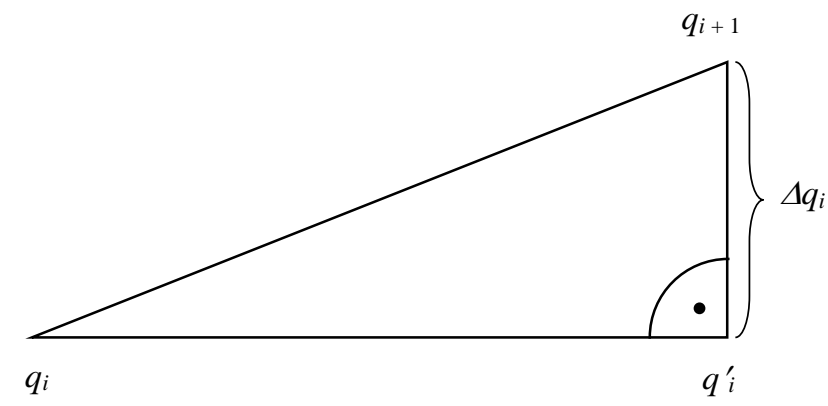

Figure no. 3. The factual trajectory $\left(q_{i}=q^{\prime}{ }_{i}\right)$ of the SEP development in $i^{\text {th }}$ time slot over period $T$

In the Figure no. 3, the factual trajectory length for the SEP development in $i^{\text {th }}$ time slot over period $T$ is equal to the line $q_{i} q_{i+1}$ of the represented triangle. The length of the perpendicular $q_{i} q_{i}^{\prime}$ is estimated by dividing the total duration of period $T$ (in this case, 10 years) by the number of its time slots, i.e. $10: \frac{10}{10}=1.0$. The $\Delta q_{i}$ of the perpendicular $q_{i+1} q_{i}$ is calculated by formula:

$$
\Delta q_{i}=\left|q_{i}-\tilde{q}_{i}\right|
$$

The factual trajectory length of the SEP development over period $T$ is equal to:

$$
L_{f}=\sum_{i=1}^{n} \sqrt{1+\Delta q_{i}^{2}} .
$$

Estimation of the SEP development dynamics index. With reference to formulas (6) and (10), the index representing the SEP development smoothness over period $T$ can be estimated as follows:

$$
D_{T}=\frac{L_{T}}{L_{F}}=\frac{\sqrt{T^{2}+\Delta Q^{2}}}{\sum_{i=1}^{n} \sqrt{1+\Delta q_{i}^{2}}},
$$

here: $D_{T}$ marks the index representing the SEP development smoothness over period $T$.

Formula (11) shows that the SEP development smoothness value in an ideal situation is equal to 1 regardless of the existing development intensity. Based on the MDD methodology for the quantitative analysis of the dynamics of SEP development, the smoothness indicator should be applied in combination with the development intensity indicator. The MDD methodology proposes to estimate this index based on formula (5). A deeper analysis of its implication, however, shows that the methodology calls for improvement. In an ideal case, the SEP development smoothness $D_{T}=1.0$. If $\Delta Q=0$ (Figure no. 1), then $Q_{f}=Q_{b}$ and $D_{I}=1.0$, while $D=1.0$. This goes against logic because if $\Delta Q=0$, i.e. if no SEP development over period $T$ has been observed, the SEP dynamics 
index should be equal to 0. Considering this, the SEP development intensity index should be estimated as follows:

$D_{I}=\frac{Q_{f}-Q_{b}}{Q_{f}}$.

Formula (13) indicates that when $Q_{f}=Q_{b}$, then $D_{I}=0$. With growing $\Delta Q$, i.e. the difference $Q_{f}-Q_{b}$, the value of the SEP development intensity index is also rising.

Formula (5), for the quantitative analysis of the dynamics of SEP development, remains unchanged, only both of its variables - the development smoothness $D_{T}$ and the development intensity $D_{I}$ - are determined in a different way:

$\bar{D}=D_{T} \cdot D_{I}=\frac{Q_{f}-Q_{b}}{Q_{f}} \cdot \frac{\sqrt{T^{2}+\Delta Q^{2}}}{\sum_{i=1}^{n} \sqrt{1+\Delta q_{i}^{2}}}$.

The economic development analysis in different countries revealed that there exists a rather elastic relationship between the development smoothness and intensity: when intensity is growing, smoothness is decreasing (Ginevičius, et al., 2018). This proposes that formula (5), representing the SEP development dynamics, should incorporate both quantitative and qualitative factors affecting this dynamics. Methods that take into account both the values and significance of the indicators, i.e. multi-criteria assessment methods (Hwang and Yoon, 1981; Hwang and Lin, 1987), are best suited for this purpose. These days multi-criteria assessment methods are applied for quantitative assessment of a wide variety of complex engineeringtechnological (Álvarez, et al., 2017; Juodagalvienė, 2018; Bielinskas, 2018; Binkytè, 2018), socio-economic (Ejdys, et al., 2016; Gedvilaite, 2018; Oželienè, 2019; Volkov, 2018) and other phenomena and processes. Some of them are less (Hwang and Yoon, 1981; Hwang and Lin, 1987; Zavadskas, et al., 1994), while others are more sophisticated (Balcomb and Curtner, 2000; Saaty, 1980; Vallee and Zielniewicz, 1994; Hwang and Yoon, 1981).

In any case, the philosophy of multi-criteria assessment is embodied in the most common classical SAW (Simple Additive Weighting) method, expressed as follows (MacCrimmon 1968; Hwang and Yoon 1981):

$k_{j}=\sum_{j=1}^{n} \omega_{i} \cdot \tilde{q}_{i}$,

here $k_{j}$ marks the value of the multi-criteria assessment by the SAW method estimated for $j^{\text {th }}$ variation of a phenomenon under consideration; $\omega_{i}$ is the significance of the $i^{\text {th }}$ indicator; $\tilde{q}_{i}$ - a normalised value of the $i^{\text {th }}$ indicator.

Based on formula (14), the SEP development dynamics is quantitatively assessed as follows:

$\widetilde{D}=\omega_{1} \cdot D_{I}+\omega_{2} \cdot D_{T}$,

here $\tilde{D}$ - the SEP development dynamics index incorporating the significance of both the development intensity and smoothness; $\omega_{1}-$ the SEP development intensity significance; $\omega_{2}-$ the SEP development smoothness significance. 
3. Analysis of the economic development dynamics of in Cyprus and Romania (2009-2018)

Quantitative analysis methodology for the dynamics of SEP development, which is referred to as MDD-M, will be illustrated by the assessment of the GDP per capita shifts in Cyprus and Romania over the 2009-2018 period (Jia, et al., 2017; Čiegis, et al., 2010; Chursan, 2013; Babu and Datta, 2015; Bolcarova and Košta, 2015; Lisiński, et al., 2020; Molendowski and Petraškevičius, 2020; Nikonenko, et al., 2020; Radlińska, et al., 2020). The abovementioned countries were selected due to the significant differences in the nature of their economic development observed over the period under consideration (Table no. 1, Figure no. 4).

Table no. 1. Data of GDP per capita in Cyprus and Romania (2009-2018)

\begin{tabular}{|l|c|c|c|c|c|c|c|c|c|c|}
\hline \multirow{2}{*}{ Country } & \multicolumn{10}{|c|}{ Year } \\
\cline { 2 - 12 } & $\mathbf{2 0 0 9}$ & $\mathbf{2 0 1 0}$ & $\mathbf{2 0 1 1}$ & $\mathbf{2 0 1 2}$ & $\mathbf{2 0 1 3}$ & $\mathbf{2 0 1 4}$ & $\mathbf{2 0 1 5}$ & $\mathbf{2 0 1 6}$ & $\mathbf{2 0 1 7}$ & $\mathbf{2 0 1 8}$ \\
\hline Cyprus & 23.1 & 23.3 & 23.2 & 22.6 & 21.0 & 20.7 & 20.9 & 21.7 & 22.8 & 24.3 \\
\hline Romania & 6.1 & 6.2 & 6.5 & 6.6 & 7.2 & 7.6 & 8.1 & 8.6 & 9.6 & 10.5 \\
\hline
\end{tabular}

Source: compiled by the author with reference to Eurostat, 2020

Cyprus GDP

Romania GDP

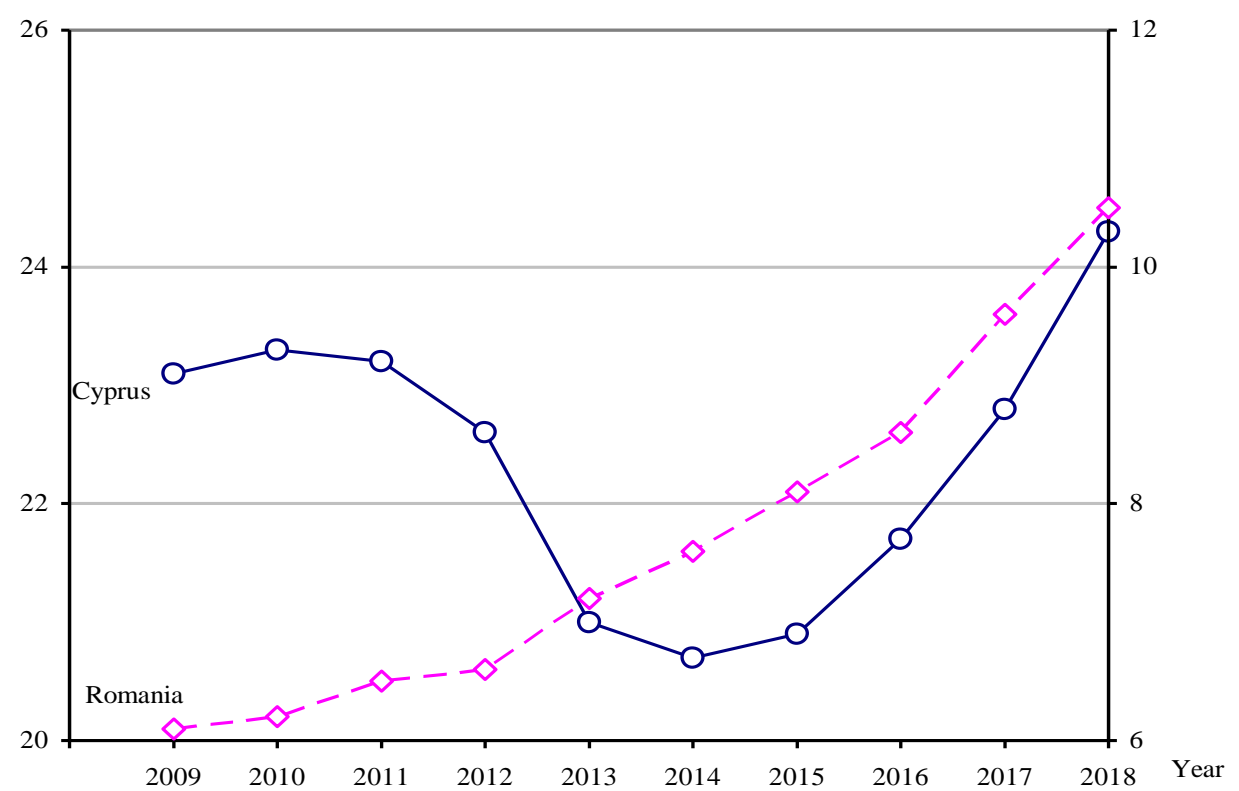

Figure no. 4. Changes in GDP per capita data in Cyprus (axis 1) and Romania (axis 2) over the 2009-2018 period

Source: compiled by the author with reference to Eurostat, 2020

Table no. 2 shows the values for the variables $Q_{b}, Q_{f}, \Delta Q$ and $\Delta \tilde{q}$. 
Table no. 2. The values of indicators $Q_{b}, Q_{f}, \Delta Q$ and $\Delta \tilde{q}$ for the economic development in Cyprus and Romania over the 2009-2018 period

\begin{tabular}{|l|c|c|c|c|}
\hline \multirow{2}{*}{ Country } & \multicolumn{4}{|c|}{ Indicator values, EUR } \\
\cline { 2 - 5 } & $\boldsymbol{Q}_{\boldsymbol{b}}$ & $\boldsymbol{Q}_{\boldsymbol{f}}$, & $\boldsymbol{\Delta Q}$ & $\boldsymbol{\Delta} \tilde{\boldsymbol{q}}$ \\
\hline Cyprus & 23.1 & 24.3 & 1.2 & 0.133 \\
\hline Romania & 6.1 & 10.5 & 4.4 & 0.489 \\
\hline
\end{tabular}

The ideal trajectory of GDP fluctuations in the countries under consideration over the 2009 2018 period can be depicted as follows (Figures no. 5-6):

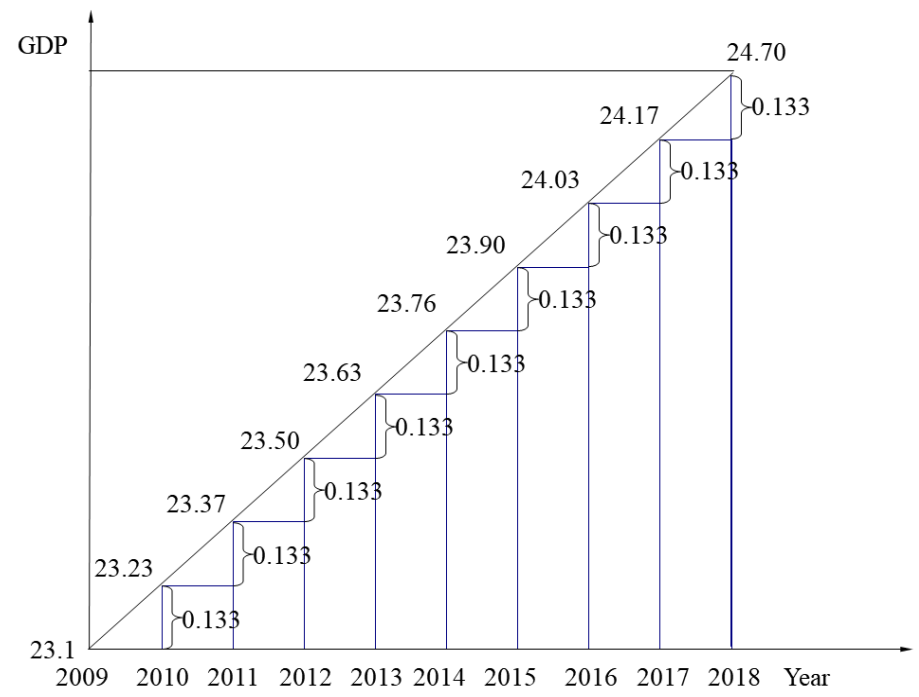

Figure no. 5. The ideal trajectory of GDP fluctuations in Cyprus over the 2009-2018 period

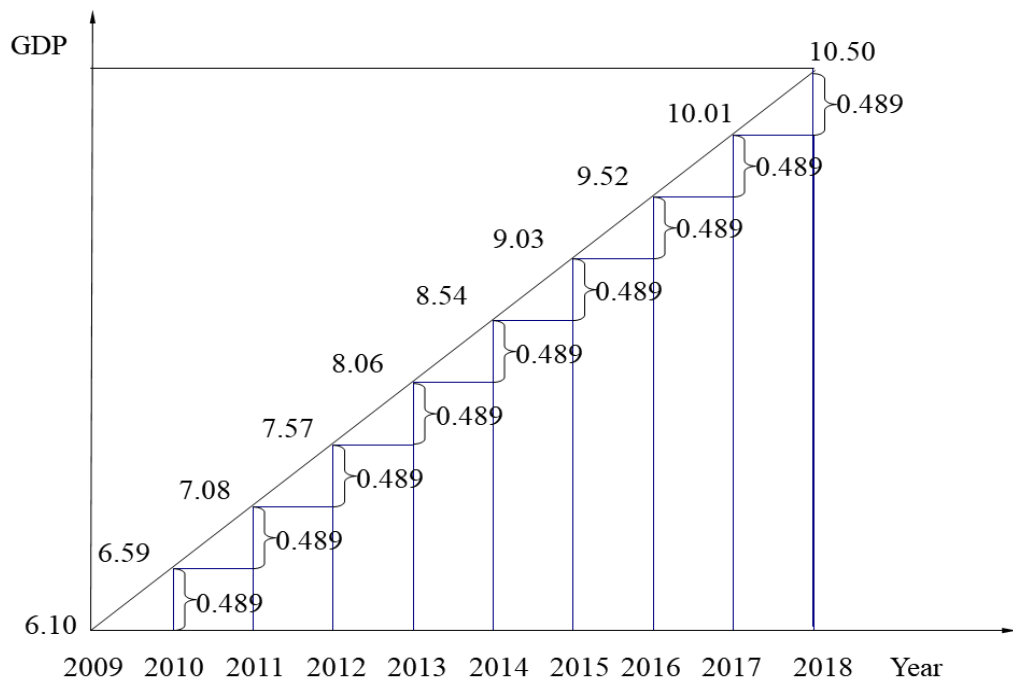

Figure no. 6. Representation of the ideal trajectory of the GDP changes in Romania 
Further analysis based on formulas (10)-(13), shows that values $L_{I}$ and $L_{f}$ be regarded as the ideal and factual trajectories lengths of the economic development in the countries under consideration over the 2009-2018 period were estimated along with the development intensity indicator $D_{I}$ and the development dynamics indicator $D_{T}$ (Table no. 3).

Table no. 3. Economic development dynamic factors in Cyprus and Romania over the 2009-2018 period

\begin{tabular}{|l|c|c|c|c|c|}
\hline \multirow{2}{*}{ Country } & \multicolumn{5}{|c|}{ Indicator values, EUR } \\
\cline { 2 - 6 } & $\boldsymbol{L}_{\boldsymbol{I}}$ & $\boldsymbol{L}_{\boldsymbol{f}}$, & $\boldsymbol{D}_{\boldsymbol{I}}$ & $\boldsymbol{D}_{\boldsymbol{T}}$ & $\overline{\boldsymbol{D}}$ \\
\hline Cyprus & 9.08 & 11.32 & 0.05 & 0.802 & 0.04 \\
\hline Romania & 10.02 & 10.29 & 0.42 & 0.974 & 0.41 \\
\hline
\end{tabular}

Table no. 3 shows that the values of GDP fluctuation smoothness over the 2009-2018 period are high. This is because the phenomenon under consideration, i.e. GDP fluctuation, is extremely complex. The development of such phenomena is always characterised by great inertia. This characteristic resonates with one of the laws of physics proposing that mass is a measure of inertia.

For the comparison of GDP development dynamics in both countries, it is necessary to assess the level they have achieved. For this purpose, coefficient $K_{j}$ will be employed:

$$
K_{j}=\frac{Q_{f j}}{Q_{f}^{\max }},
$$

$K_{j}-$ is the coefficient for the economic development intensity adjustment of in the $j$ th country in relation to the other country;

$Q_{f j}$ - is the economic development value of the $j_{\text {th }}$ country at the end of the analysed period; $Q_{f}^{\max }$ - is the economic development value of the country which is higher at the end of the analysed period.

For further analysis formulas (12) and (16), are used for the evaluation of the intensity of the economic development in the $j_{t h}$ country in relation to the other country:

$\tilde{D}_{j}=\frac{Q_{f j}-Q_{b j}}{Q_{f}^{\max }}=\frac{\Delta Q_{j}}{Q_{j}^{\max }}$.

After application of the formula (17) and reassessment of the economic development intensity indicator in the analysed countries, the development dynamics values also changed (Table no. 4):

Table no. 4. Economic development dynamics indicators of the Cyprus and Romania based of the context of the other country (2009-2018)

\begin{tabular}{|l|c|c|c|}
\hline \multirow{2}{*}{ Country } & \multicolumn{3}{|c|}{ Indicator values } \\
\cline { 2 - 4 } & $\boldsymbol{D}_{\boldsymbol{j}}$ & $\boldsymbol{D}_{\boldsymbol{T} \boldsymbol{j}}$ & $\boldsymbol{D}$ \\
\hline Cyprus & 0.05 & 0.802 & 0.04 \\
\hline Romania & 0.18 & 0.974 & 0.18 \\
\hline
\end{tabular}

For the evaluation of the development intensity and smoothness impact on the development dynamics, it is important to evaluate the significance those indicators on the development 
process. The expert evaluation showed that $\omega_{1}=0.7$, while $\omega_{2}=0.3$, which defines the development dynamics indicator values (Table no. 5):

Table no. 5. Economic development dynamics indicators based on the significance of the development intensity and smoothness (2009-2018)

\begin{tabular}{|l|c|}
\hline \multicolumn{1}{|c|}{ Country } & The value of the economic development dynamics indicator \\
\hline Cyprus & 0.28 \\
\hline Romania & 0.54 \\
\hline
\end{tabular}

Implemented analysis shows that the dynamics indicator value is more affected by the development intensity rather than the development smoothness.

\section{Conclusions}

1. In order to increase the efficiency of correlation-regression analysis, which these days is the most common method of the SEP analysis and fluctuation forecast, both independent, i.e. input, and dependent, i.e. output, variables need to be expressed in their dynamic rather than static condition. For this purpose, their fluctuations over a particular period, i.e. the dynamics of their fluctuations, need to be quantitatively assessed.

2. The main point if the SEP development dynamics quantitative analysis is the difference ratio between the ideal and the factual trajectory lengths of the development. Ideal trajectory length reflects the maximum possible smoothness. The current MDD (Measuring of Dynamics of Development) methodology calls for improvement for several reasons: firstly, it does not fully reflect the real SEP development; also, the factual trajectory length of the SEP development in all cases is compared with the duration of analysed time period $T$.

3. Based on the proposed methodology, which is named as MDD-M, SEP development factual trajectory length is evaluated based on the length of the diagonal line in the triangle. Perpendicular in this triangle represents the SEP development scale over the analysed period of time, while the other one is represents to the duration of this time period.

4. For the evaluation of the SEP development factual trajectory length the sum of the diagonals in the triangles based on separate time slots inside the analysed whole time period. In order to evaluate the length of a perpendicular inside triangles it is needed to divide the total duration of the analysed time period by the number of separate time slots. In this analysis the length of another perpendicular is evaluated as the difference between the the development factual value at the end of the $i^{\text {th }}$ time slot and the ideal trajectory value in this time slot.

5. The more accurate result of quantitative assessment is obtained by considering the significance of both quantitative and qualitative sides of the SEP development, represented by the development intensity and smoothness respectively.

The proposed quantitative assessment methodology, for the analysis of the SEP development dynamics, can be applied not only to raise the adequacy of correlationregression. It can also be applied for analysing the development of various socio-economic processes: assessment of GDP, investment, sectoral economic, social, shadow economy related fluctuations and tendencies, etc. 


\section{References}

Álvarez, M.E.P., Bárcena, M.M. and González, F.A., 2017. On the sustainability of machining processes. Proposal for a unified framework trough the triple bottom-line from an understanding review. Journal Cleaner Production, 142(4), pp. 3890-3904.

Babu, S. and Datta, S.K., 2015. Revisiting the link between socio-economic development and environmental status indicators-focus on panel data. Environment, Development and Sustainability, 17(3), pp. 567-586.

Balcomb, J.D. and Curtner, A., 2000. MCDM-23: multi-criteria decision making fool for buildings. Maastricht: s.n., pp.219-221.

Bielinskas, V., 2018. Evaluation of scenarios for changer in the purpose of urban brownfields applying multi-attribute decision making methods. Doctoral dissertation. Vilnius: Technika.

Binkytè, A., 2018. Big data analytics recommender system for housing health and safety. Doctoral dissertation. Vilnius: Technika.

Bolcarova, P. and Kološta, S., 2015. Assessment of sustainable development in the EU27 using aggregated SD index. Ecological Indicators, 48, pp.699-705. DOI: 10.1016/ j.ecolind.2014.09.001.

Chursan, S., 2013. Assessing the Sustainable Development in Thailand. Procedia. Environmental Sciences, 17, pp.611-619.

Čiegis, R., Ramanauskienè, J. and Šimanskienè, L., 2010. Lietuvos regionu darnaus vystymosi vertinimas [Assessment of the sustainable development in Lithuanian regions]. Klaipeda: Klaipedos universiteto leidykla.

Ejdys, J., Matuszak-Flejszman, A., Szymanski, M., Ustinovichius, L., Shevchenko, G. and Lulewicz-Sas, A., 2016. Crucial factors for improving the ISO 14001 environmental management system. Journal of Business Economics and Management, 17(1), pp.52-73.

Eurostat, 2020. Eurostat. Your key to European statistics. [online] Available at: <https://ec.europa.eu/eurostat> [Accessed 2 September 2020].

Gedvilaite, D., 2019. The assessment of sustainable development of a country's regions. Doctoral dissertation. Vilnius: Technika.

Ginevičius, R., Gedvilaitė, D., Stasiukynas, A. and Šliogerienė, J., 2018. Quantitative assessment of the dynamic of the economics development of socioeconomic systems based on the MDD method. Inžinerine ekonomika (Engineering Economics), 29(3), pp.264-271.

Hwang, C.L. and Lin, M.-J., 1987. Group Decision Making under Multiple Criteria: Methods and Applications. Berlin-Heidelberg: Springer.

Hwang, C.L. and Yoon, K., 1981. Multiple attribute decision-making methods and Applications. A state of the art survey. Lecture Notes in Economics and Mathematical Systems 186. Berlin: Springer-Verlag.

Jia, X., Foo, D.C.Y., Tan, R.R. and Li, Z., 2017. Sustainable development paths for resource-constrained process industries. Resources, Conservation and Recycling, 119(C), pp. 1-13. DOI 10.1016/j.resconrec.2016.11.004.

Juodagalvienè, B., 2018. Multiple criteria selection of design solutions for single-family houser. Doctoral dissertation. Vilnius: Technika. 
Lisiński, M., Augustinaitis, A., Nazarko, L. and Ratajczak, S., 2020. Evaluation of dynamics of economic development in Polish and Lithuanian regions. Journal of Business Economics and Management, 21(4), pp. 1093-1110.

MacCrimmon, K.R., 1968. Decision making Among Multiple-Attribute Alternatives. A Survey and Consolidated Approach, s.l.: RAND Memorandum RM-4823-ARPA.

Molendowski, E. and Petraškevičius, V., 2020. International competitive positions of the Baltic States - changes and determinants in the post-accession period. Journal of Business Economics and Management, 21(3), pp. 706-724.

Nikonenko, U., Hanushchyn, S., Boikivska, G., Andriichuk, Y. and Kokhan, V., 2020. Influence of world commodity prices on the dynamics of income of exporting countries of natural resources under globalization. Business: Theory and Practice, 21(1), p. 440.

Oželienè, D., 2019. Modelling the factors of a company's sustainable development. Doctoral dissertation. Vilnius: Technika.

Radlińska, K., Klonowska-Matynia, M., Jakubowska, A. and Kwiatkowski, G., 2020. Labor hoarding: an old phenomena in modern times? Case study for EU countries. Journal of Business Economics and Management, 21(3), pp. 872-889.

Saaty, T.L., 1980. The Analytic Hierarchy Process. New York: McGraw-Hill.

Vallee, D. and Zielniewicz, P., 1994. ELECTRE III-IV, Version 3x. Aspects Methodologiques (tome 1). Paris: Universite de Paris Dauphine.

Volkov, A., 2018. Assessment of the impact of the common agricultural policy direct payments system on agricultural sustainability. Doctoral dissertation. Vilnius: Technika.

Zavadskas, E.K., Kaklauskas, A. and Sarka, V., 1994. The new method of multicriteria complex proportional assessment of projects. Technological and Economic Development of Economy, 1(3), pp. 131-139. 